\title{
PRÁTICAS EDUCATIVAS QUE CONTRIBUEM PARA A GARANTIA DOS DIREITOS FUNDAMENTAIS EM UMA INSTITUIÇÃO SOCIOEDUCATIVA: A EDUCAÇÃO QUE TRANSFORMA
}

\author{
EDUCATIONAL PRACTICES CONTRIBUTING TO GUARANTEE \\ FUNDAMENTAL RIGHTS IN A SOCIO-EDUCATIONAL INSTITUTION: \\ EDUCATION THAT TRANSFORMS
}

\section{PRÁCTICAS EDUCATIVAS QUE CONTRIBUYEN A GARANTIZAR LOS DERECHOS FUNDAMENTALES EN UNA INSTITUCIÓN SOCIOEDUCATIVA: EDUCACIÓN QUE TRANSFORMA}

\author{
Emerson Aparecido Augusto \\ Mestrando em Educação - UNIARA \\ Email: mersonaugusto@yahoo.com.br \\ Igor Terezane Nardocci \\ Mestrando em Educação - UNIARA \\ Email: igor_nar@hotmail.com \\ Ubirajara Donisete Ferreira Leão \\ Mestrando em Educação - UNIARA \\ Email: ubirajara.leao@ifsp.edu.br \\ Edmundo Alves de Oliveira - UNIARA \\ Doutor em Sociologia - UNESP \\ Email: edmundoedmundo@gmail.com
}

\section{RESUMO}

Este artigo propõe uma breve reflexão sobre a importância de se discutir, durante a elaboração do Projeto Político Pedagógico de uma Instituição Socioeducativa, práticas educacionais que garantam a manutenção dos direitos humanos para todos os adolescentes em regime de internação, uma vez que a garantia desses direitos está prevista na constituição brasileira de 1988 e nos tratados dos quais o Brasil é membro. Para a efetividade do PPP é necessária uma gestão democrática e participativa entre os envolvidos, pais ou responsáveis, alunos, professores, gestores e todos que direta ou indiretamente, contribuem para a formação desses jovens. A discussão dos direitos fundamentais é relevante, pois norteia o planejamento de metodologias pedagógicas, capaz de preencher lacunas na formação do jovem infrator, proporcionando oportunidades concretas de reintegração social. A garantia de uma educação transformadora, precisa ser germinada nas discussões que antecedem a elaboração do PPP e ser posta em prática durante a estadia do adolescente em uma instituição socioeducativa. De todos os diretos 
fundamentais e ou universais, entendemos ser inquestionável a importância do direto à vida, entretanto, para se ter esse discernimento ou qualquer outro questionamento de caráter filosófico ou científico é necessária uma formação no mínimo crítica sobre si mesmo e seu papel na sociedade, ou seja, é necessária a garantia de uma educação formadora.

Palavras-chave: Projeto Político Pedagógico; Direitos Humanos; Práticas de Ensino.

\begin{abstract}
The present article proposes a brief reflection on the importance of discussing, during the elaboration of the Political Educational Project of a Socioeducational Institution, educational practices that guarantee the maintenance of the human rights for all the adolescents in hospitalization regime, since the guarantee of these rights is foreseen in the Brazilian constitution of 1988 and in the treaties of which Brazil is a member. For the effectiveness of the PPP, a democratic and participative management is necessary between those involved, parents or guardians, students, teachers, managers and all that directly or indirectly, contribute to the formation of these young people. The discussion of fundamental rights is relevant, as it guides the planning of pedagogical methodologies, capable of filling gaps in the training of the young offender, providing concrete opportunities for social reintegration. The guarantee of a transformative education must be germinated in the discussions that precede the elaboration of the PPP and be put into practice during the stay of the adolescent in a socio-educational institution. Of all the fundamental and universal rights, we understand that the importance of directness to life is unquestionable; however, in order to have this discernment or any other questioning of a philosophical or scientific character, a minimum of critical formation about himself and his role in society, that is, the guarantee of a formative education is necessary.
\end{abstract}

Keywords: Political Pedagogical Project; Human rights; Teaching Practices.

\title{
RESUMEN
}

Este artículo propone una breve reflexión sobre la importancia de discutir, durante la elaboración del Proyecto Político Pedagógico de una Institución Socioeducativa, prácticas educativas que garanticen el mantenimiento de los derechos humanos para todos los adolescentes hospitalizados, desde la garantía Estos derechos están previstos en la Constitución brasileña de 1988 y los tratados a los que Brasil es embroil. Para la efectividad del PPP, se requiere una gestión democrática y participativa entre los involucrados, padres o tutores, estudiantes, maestros, gerentes y todos aquellos que directa o indirectamente contribuyen a la formación de estos jóvenes.La discusión de los derechos fundamentales es relevante porque guía la planificación de metodologías pedagógicas, capaces de llenar vacíos en la formación de delincuentes juveniles, brindando oportunidades concretas para la reintegración social.La garantía de una educación transformadora debe germinar en las discusiones que preceden a la elaboración del PPP y ponerse en práctica durante la estadía del adolescente en una institución coeducational. De todos los derechos fundamentales y universales, entendemos que la importancia del derecho a la vida es incuestionable, sin embargo, para tener este discernimiento o cualquier otro cuestionamiento filosófico o científico, es necesario tener al menos una formación crítica sobre uno mismo y su papel en la sociedad. es decir, la garantía de una educación formativa es necesaria.

Palabras clave: Proyecto político pedagógico; Derechos humanos; Prácticas de enseñanza. 


\section{INTRODUÇÃO}

Sem pretensão de esgotar a temática, esse texto tem por finalidade a abordagem dos direitos fundamentais, numa instituição socioeducativa pública, por intermédio da Educação;

Obrigatória, gratuita e universal, a educação só poderia ser ministrada pelo Estado. Impossível deixá-la confiada a particulares, pois estes somente podiam oferecê-la aos que tivessem posses (ou a protegidos), e daí operar antes para perpetuar as desigualdades sociais, que para removê-las (TEIXEIRA, 1957, p.27).

Em uma instituição de ensino que tenha por missão:

Executar, direta ou indiretamente, as medidas socioeducativas com eficiência, eficácia e efetividade, garantindo os direitos previstos em lei e contribuindo para o retorno do adolescente ao convívio social como protagonista de sua história (FUNDAÇÃO CASA).

[....] é imprescindível a criação de um ambiente acolhedor e reparador de perdas que muitas vezes são resultados distorcidos ou ausência da manutenção desses direitos após a reintegração do adolescente, quando inserido no convívio social.

Devido a essas demandas, a garantia dos direitos humanos precisa ser prevista e discutida democraticamente nas reuniões voltadas para a elaboração do Projeto Político Pedagógico - PPP de uma Instituição Socioeducativa, sendo propostas práticas educacionais que garantam esses direitos para todos os adolescentes em medida socioeducativa, principalmente, aqueles que se encontra em regime de internação.

Educar para os direitos humanos, prescinde então de uma escuta sensível e de uma ação compartilhada entre professores e alunos, capaz de desencadear processos autônomos de produção de conhecimento (DIAS, 2007, p.453).

Para a efetividade do PPP é necessária uma gestão democrática e participativa entre os envolvidos, pais ou responsáveis, alunos, professores, gestores e todos que direta ou indiretamente, contribuem para a formação desses jovens.

A discussão dos direitos fundamentais é relevante, pois norteia o planejamento de metodologias pedagógicas, capaz de preencher lacunas na formação do jovem infrator, proporcionando oportunidades concretas de reintegração social. A garantia de uma educação 
transformadora, precisa ser germinada nas discussões que antecedem a elaboração do PPP, e, ser posta em prática durante a estadia do adolescente em uma instituição socioeducativa.

Com isso, pelo viés de uma educação emancipadora, embasada no DH, é possível uma transformação efetiva dos jovens para além das "grades" de internação, ao se oferecer condições suficientes a uma mudança de paradigma, seja econômica ou social, onde:

A consciência do ser-no-mundo se mostra como uma ferramenta que possibilita a construção de sujeitos sociais críticos e atuantes em uma determinada sociedade, cônscios de seu inacabamento e, por isso mesmo, capazes de serem protagonistas de sua própria história (DIAS, 2007, p. 453).

\section{SOBRE OS DIREITOS HUMANOS}

Após a Segunda Guerra Mundial, diante de tamanha devastação sem precedentes, fruto da ambição entre povos, os representantes das nações vitoriosas, em 1945, criam a ONU (Organização das Nações Unidas). Seu objetivo ao substituir à Liga das Nações era, em primeira instância, o de promover a paz mundial.

Em 1948, a ONU vê a necessidade de se criar a Declaração Universal dos Direitos Humanos (DUDH), garantindo os direitos fundamentais a todo e qualquer ser humano, independente de gênero, crença ou nacionalidade.

Entende-se por Direitos Humanos:

[....] aqueles direitos considerados fundamentais a todos os seres humanos, sem quaisquer distinções de sexo, nacionalidade, etnia, cor da pele, faixa etária, classe social, profissão, condição de saúde física e mental, opinião política, religião, nível de instrução e julgamento moral (BEVENIDES, 2000, p. 3).

Entre os direitos fundamentais está o direito à vida, considerada a base que sustenta os demais direitos estampados no artigo $5^{\circ}$ da nossa constituição:

Todos são iguais perante a lei, sem distinção de qualquer natureza, garantindo-se aos brasileiros e aos estrangeiros residentes no País a inviolabilidade do direito à vida, à liberdade, à igualdade, à segurança e à propriedade. (Constituição Federal 1988).

$\mathrm{O}$ direito à vida, ou de se permanecer vivo, também está presente no artigo $3^{\circ}$ da Declaração Universal dos Direitos Humanos, conforme texto a seguir: 
Todo indivíduo tem direito à vida, à liberdade e à segurança pessoal (DUDH, 1948). Mas, o próprio conceito da palavra vida pode ter definições diferentes entre povos e nações, até mesmo num país de proporções continentais e pluriculturais como é o caso do Brasil.

Qualquer que seja o sentido dado a este signo linguístico e as discussões políticas, religiosas ou científicas sobre o seu significado, o direito à vida é inviolável e há de se prevalecer sobre os demais, garantindo a todas as pessoas condições suficientes e necessárias para uma vida digna, com respeito às diferenças e oportunidades iguais, sendo uma destas, a oportunidade e o direito de se ter uma educação de qualidade, cujo objetivo seja o de proporcionar condições mínimas e necessárias às pessoas que vivem às margens da sociedade, em situação vulnerável, para que através do e pelo conhecimento, essas pessoas possam transformar a si mesma e toda a população no seu entorno.

De acordo com Konder (1992), uma educação transformadora apresenta-se como:

[.... a atividade concreta pela qual os sujeitos humanos se afirmam no mundo, modificando a realidade objetiva e, para poderem alterá-la, transformando-se a si mesmos. É a ação que, para se aprofundar de maneira mais consequente, precisa da reflexão, do autoquestionamento, da teoria; e é a teoria que remete à ação, que enfrenta o desafio de verificar seus acertos e desacertos, cotejando-os com a prática (KONDER, 1992, p.115).

O Brasil, respeitando a sua diversidade cultural e suas peculiaridades regionais, possui desafios gigantescos para a garantia plena dos direitos fundamentais, um desses "gargalos" está no rompimento de uma educação tradicional e elitista, tida, respectivamente, como a apropriação cultural e científica de gerações passadas em forma de transmissão de conhecimento, para uma minoria letrada da população brasileira.

Não é objetivo desse artigo o aprofundamento das questões ideológicas que influenciam nas políticas públicas educacionais, ainda que tais questões sejam relevantes para as reflexões ao longo do tema abordado, manteremos a retórica da educação como um direito de todos, entretanto, uma provocação que precisa ser feita e esclarecida é a de qual educação estamos discorrendo e se instruir é sinônimo de educar, hoje em dia.

De acordo com o dicionário Aurélio, "instruir é ensinar a fazer algo; dar ou adquirir instrução", entre outras significações: 
Instrução não é o mesmo que educação: a primeira refere-se ao pensamento, a segunda, principalmente aos sentimentos. Embora não exista boa educação sem instrução. As qualidades morais aumentam de preço quando são realçadas pelas qualidades inteligentes (CALLEJA, 2008, p.109).

Para Saviani, é a educação que diferencia o "homem" dos animais, uma vez que o ser humano tem a capacidade de apropriar-se da cultura e dos conhecimentos produzidos por seus ancestrais e produzir novos conhecimentos. Dessa forma, entendemos que a educação não pode ser compartimentada, embalada como um produto a ser oferecido nas gôndolas das lojas, no atacado ou varejo, objeto de uma instrução sistemática. Ela precisa ser dinâmica, interativa e significativa. Para além da profissionalização de nossos jovens e adultos, precisamos ensiná-los a "pescar o peixe" ainda que o mar não esteja para isso.

Dessa maneira;

A educação é um pré-requisito necessário à liberdade civil, pois os direitos civis se destinam a ser utilizados por pessoas inteligentes e de bom senso, que aprenderam a ler e escrever (FERNANDES \& PALUDETO, 2010, p.234).

Inferimos que o conhecimento, além de ser necessário à liberdade civil, é suficiente e capaz de romper com as barreiras ideológicas que falsamente harmonizam as estruturas sociais, onde se tem na maioria das grandes cidades, um número expressivo de pessoas sobrevivendo em condições sub-humanas.

Compreender o mundo em que se vive, com nuances e desafios locais, compreender e respeitar as diversidades, entender sua condição social como condição mutável e visualizar possibilidades de transformação, esse tem que ser o legado de uma práxis educadora para nossos jovens, principalmente àqueles que se encontram em situação de exclusão e vulnerabilidade sociais.

Percebe-se que os direitos humanos devem ser tratados e discutidos no ambiente escolar, pela comunidade acadêmica e seus pares, pois se a educação liberta repara e constrói, uma má educação pode romper com os pilares dos direitos conquistados pela humanidade historicamente.

\section{CENÁRIO CATASTRÓFICO E MUDANÇA DE PARADIGMA}


No PPP (Projeto Político Pedagógico), de uma instituição de ensino, há que se estabelecer estratégias para a garantia dos direitos fundamentais aos alunos, principalmente na questão educacional. Não o fazendo, durante as reuniões que antecedem a formulação do PPP, cercearemos a classe discente dos direitos à cultura, à liberdade, ao conhecimento herdado de gerações passadas, enfim a uma educação completa e significativa.

Qualquer debate acerca de metas educacionais carece de significado e importância frente a essa meta: que Auschwitz não se repita. Ela foi à barbárie contra a qual se dirige toda a educação (ADORNO, 1995, p.119).

Pensar que nós, enquanto educadores, falhamos ou que a "educação" no contexto amplo, não foi o suficiente para evitar as atrocidades da Grande Guerra, deixa-nos perplexos, impotentes na solução deste questionamento. Junto com o conhecimento crítico, ao lado dos avanços tecnológicos há de se pensar e discutir o papel humano nas ciências.

Para que" Auschwitz não se repita" e garantirmos o alicerce que sustenta os fundamentos dos direitos humanos, é imprescindível discutirmos o papel da Educação no cenário mundial.

Conceber a educação como direito humano diz respeito a considerar que as pessoas se diferenciam dos outros seres vivos por uma característica inerente à sua espécie: a vocação de produzir conhecimento e, por meio dele, transformar a natureza, organizar-se socialmente e elaborar cultura (GRACIANO, 2005, p.16).

Grosso modo, é inegável que após Auschwitz, existe um esforço conjunto entre governos para a manutenção da paz mundial, no entanto guerras localizadas, conflitos entre povos por diversas razões persistem, e o número de pessoas civis ou militares que perderam suas vidas somente na guerra da Síria, nos últimos 7 anos, de acordo com estimativas da ONU ultrapassa 500.000 .

Situação pior é a do Brasil que segundo o Atlas da violência de 2018, figura 1, registrou, em 2016, 62.517 homicídios. Se considerarmos a proporcionalidade em anos com a guerra da Síria, o Brasil aproxima-se dos índices de morte por homicídios com taxas perto dos 400.000. E situação piora, quando ao se analisar os dados que compõe o atlas, constatamos que a taxa de homicídios por jovens de 100.000 jovens em 2016 está acima dos 65\%. Podemos depreender ligeiramente, que a população brasileira está envelhecendo não porque estamos vivendo mais, e sim porque grande parte da população jovem brasileira o direito à vida foi cerceado. 
O Estatuto da Criança e do Adolescente (ECA), lei 8.069, de 1990, estabelece diretrizes, alinhadas à constituição brasileira de 2018, que garantem os direitos fundamentais dos jovens entre 12 a 21 anos incompletos em cumprimento de medida socioeducativa.

De acordo com o ECA, é considerada criança uma pessoa que tenha até 12 anos de idade incompletos e adolescente quem está na faixa de 12 anos até 18 anos, em casos excepcionais e quando disposto na lei, o estatuto é aplicável até aos 21 anos de idade incompletos.

A maioria dos jovens brasileiros em situação de vulnerabilidade social está na faixa etária entre 12 a 21 anos, significa que são adolescentes com potencial para adquirirem uma formação humana, cultural e científica, ou seja, uma formação humana, cuja essência é o reconhecimento de si e do seu próximo como pessoas que merecem viver.

Para que "Auschwitz não se repita" é necessária uma compreensão crítica do que seja direitos humanos e a importância de se garantir igualmente, num país de desigualdades os direitos fundamentais, dentre esses direitos: a vida.

Figura 1: Mapa da violência

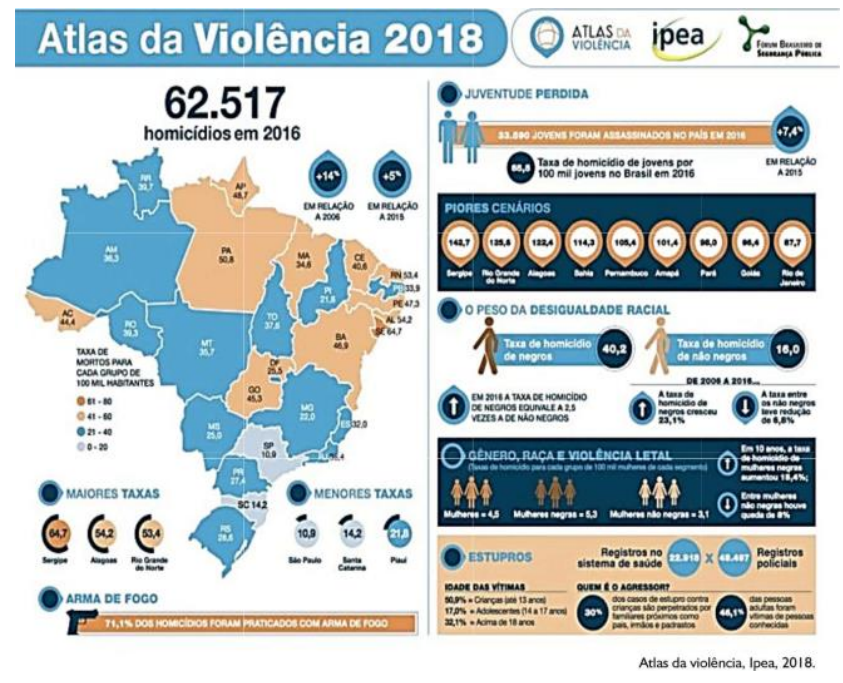

Fonte: IPEA 


\section{O PROJETO POLÍTICO PEDAGÓGICO E O PAPEL DO EDUCADOR NO MODELO SOCIOEDUCATIVO DE ENSINO}

O Projeto Político Pedagógico para ser bem-sucedido pressupõe participação ativa da comunidade, pais, alunos, gestores, professores e demais funcionários da escola; desde o esboço até a conclusão do mesmo. Sempre tendo como foco um ensino que privilegia a interação entre as disciplinas, pois, o conhecimento deve ser "multidisciplinar," no sentido de abranger várias áreas, inclusive as áreas de humanidades com ênfase aos direitos humanos.

Romper com a metodologia "tradicional" do ensino, onde vemos o professor como detentor do conhecimento e os alunos apenas como "receptores" de conteúdos educacionais, o PPP bem-sucedido, estabelece estratégias para desenvolver a autonomia dos envolvidos, despertando a curiosidade do discente, iniciando o jovem à técnica da pesquisa ao alinhar teoria $\mathrm{e}$ prática.

Entretanto, o projeto precisa ser coerente com o conteúdo curricular deste aluno, levandose em conta a aplicabilidade do mesmo, o espaço físico é de extrema relevância, assim como, toda a infraestrutura necessária para a eficácia da Educação.

Um PPP mal elaborado, ou até mesmo sem uma conexão com o contexto acadêmico, pode desqualificar os efeitos positivos que teria na educação, principalmente na educação dos adolescentes em conflito com a lei, quando internados numa instituição socioeducativa. Dessa maneira, entende-se que ignorar a importância de se discutir os direitos fundamentais dos jovens em regime de internação, estamos contribuindo para uma visão distorcida de cidadania e excluindo uma parcela expressiva da população brasileira do seu direito de aprender e oportunidade de viver dignamente.

[....] educação para a cidadania não pode partir de uma visão da sociedade homogênea, como uma grande comunidade, nem permanecer no nível do civismo nacionalista. Torna-se necessário entender educação para a cidadania como formação do cidadão participativo e solidário, consciente de seus deveres e direitos - e, então, associá-la à educação em direitos humanos (BEVENIDES, 2000, p.315).

A Fundação Centro de Atendimento Socioeducativo ao Adolescente (Fundação Casa), fundação pública, mantida e administrada pelo Governo do Estado de São Paulo, é uma instituição que assiste e acolhe os adolescentes entre 12 a 21 anos incompletos em condições de 
vulnerabilidade e conflito com a lei. Dentre os serviços prestados, denominados "medidas socioeducativas", a internação do jovem infrator, sob o viés de uma educação inclusiva cuja garantia seja os direitos fundamentais, é o objetivo do órgão público.

Pretendemos, neste artigo, analisar o caminho que esse jovem percorre, desde o instante da sua internação, o tempo de convivência nesse ambiente acolhedor até seu retorno à sociedade. Quais os impactos positivos ou negativos durante o cumprimento da medida e suas implicações para o futuro desses adolescentes?

Ressalto que é apenas um recorte, um ponto a ser analisado, pois, o tema é amplo e complexo devido às variadas interferências que uma medida de privação de liberdade possa ter. $\mathrm{O}$ adolescente quando é internado pela primeira vez, traz consigo a ideia de punição pela sua conduta nada social, sentimento de culpa, inferioridade e exclusão são visíveis na postura desse jovem.

O desafio de um educador é justamente desconstruir esses valores negativos, cristalizados pelo tempo, fazendo com que muitos desses adolescentes voltem a sonhar, acreditar em seus sonhos e ressocializar-se, reconhecendo a gravidade dos seus atos, os impactos negativos para a sociedade e que é possível a mudança de conduta na criação de oportunidades para a sua vida.

Isso requer planejamento, tanto de quem educa, quanto de quem aprende a apropriação de técnicas e conceitos empreendedores alicerçados nos fundamentos dos direitos individuais e sociais, podem fazer a diferença na vida de muitos jovens em situação de vulnerabilidade.

Passando pela fase de adaptação, esse adolescente, já demarcou seu espaço, adquiriu vínculos com funcionários e outros internos realizam as atividades de rotinas no centro de internação, alimentação, saúde, cursos diversos e recreação.

Há uma progressão, respeitando o tempo de cada adolescente, em média 6 meses depois da medida, esse adolescente é devolvido para a "comunidade" de onde saiu, com a promessa de que está livre das drogas e do "crime".

O índice oficial de reincidência de reincidência, que é o retorno do adolescente para a medida socioeducativa, é de 1954 adolescentes em fevereiro de 2018, de acordo com informações da Fundação Casa, obtidos pelo site eletrônico do UOL, conforme gráfico abaixo. Entretanto, verifica-se na prática que esta quantidade é muito maior, por vários motivos, entre eles o de que muitos adolescentes voltam a praticar atos infracionais quando saem da medida, entretanto, ou 
não foram "pegos" ainda, ou cumprem outra forma de medida socioeducativa que não seja a internação.

Figura 2: Reincidentes da Fundação Casa

\section{Reincidentes da Fundação Casa}

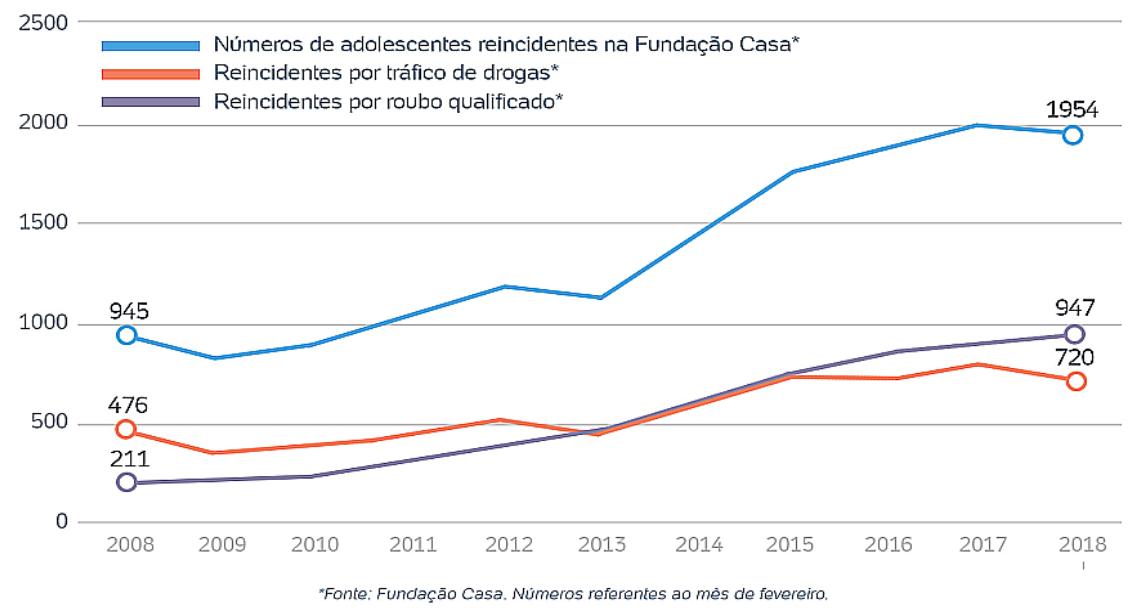

Fonte: Dados obtidos através do portal UOL - Fev. 2018.

Feitas as considerações, a proposta em se discutir medidas efetivas de garantia dos direitos fundamentais antes, durante e após a internação do adolescente, pelo viés de uma educação transformadora, é imprescindível para o rompimento desse ciclo vicioso, pois, um jovem desafortunado, num contexto social diverso, vai para um sistema que oferece tudo o que lhe foi tirado desde o seu nascimento, saúde, educação, afeto e o direito de sonhar, mas, apenas por um curto espaço de tempo, devolvendo-o depois, para o convívio social, sem algum apoio ou acompanhamento, vê seu sonho desmoronar, tornando-se impotente para mudar sua vida pessoal e profissional.

Pensar numa Educação Empreendedora, voltada para o desenvolvimento "social” de uma determinada população ou comunidade, é em primeira instância, se apropriar das teorias "Freirianas" no que diz respeito a uma educação autônoma, crítica e libertadora. (DOLABELA, 2003).

Uma pedagogia capaz de quebrar paradigmas e abalar com o tradicional modelo de educação brasileira, dualista e reprodutor de uma ideologia dominante, tendo como finalidade formar mão de obra para o mercado de trabalho. 
Paulo Freire defende a formação de um sujeito ativo, participativo e transformador. Sujeito esse, capaz de questionar a sua realidade e reconstruí-la livre de interferências ideológicas.

A proposta de uma Educação Empreendedora defendida por Dolabela (2003) dialoga com Freire, pois, tem a nobre missão de modificar as estruturas do sistema educacional brasileiro.

A começar pela questão curricular, onde verifica-se principalmente na educação de nível fundamental e médio um certo engessamento das disciplinas compartimentadas e sem interação com a prática.

A interdisciplinaridade e a pesquisa são essenciais para a formação do aluno, rompendo com a postura passiva de aprendizado, já começando a desenvolver neste aluno habilidades empreendedoras.

Também, necessário comentar que, como afirma Pacheco (2006), é um erro pensar que as pessoas nascem empreendedoras, sendo assim, somente uma educação atenta às necessidades empreendedoras de uma determinada região, poderá florescer e dar bons frutos.

Despertar o espírito de inovação, de autoestima, alimentar os sonhos de um aluno é um desafio motivador para aquele que educa, entretanto, há que se romper barreiras centenárias, onde o professor deixa seu local de prestígio, como detentor e centralizador de conhecimentos, e passa a assumir uma posição de tutor, orientador, dialogando e propondo desafios para seus alunos, contribuindo dessa maneira para a formação empreendedora dos mesmos.

Uma educação empreendedora, fundamentada em valores éticos e morais é a proposta de intervenção para romper esse ciclo, e deveria num primeiro momento, ser discutida com a sociedade, para posterior definição, no PPP.

\section{CONSIDERAÇÕES FINAIS}

Buscou-se compreender, neste artigo, a importância de práticas pedagógicas cujo propósito seja o de promover uma educação formadora e autônoma, transformando os jovens, em cumprimento de medida socioeducativa, em sujeitos críticos e empreendedores. Alinhada a essa metodologia de ensino, percebemos a importância da discussão, durante a elaboração do Projeto Político Pedagógico, de temas transversais, como a garantia e manutenção dos direitos humanos 
ao longo da permanência dos adolescentes na instituição socioeducativa e posterior a ela, quando o jovem volta ao convívio social.

Entendemos que a reflexão dos direitos fundamentais no contexto educacional, assim como, no ambiente familiar do adolescente, contribuirá de maneira eficaz para uma mudança de postura e possibilidades de ascensão social. O resultado que se espera é um mundo mais igual, humano e com uma taxa mortandade por homicídios menor, principalmente entre jovens de 18 a 21 anos de idade.

\section{REFERÊNCIAS}

ADORNO, T.W. Educação após Auschwitz. In: __. Palavras e sinais. Trad., notas e glossário de Maria Helena Rupichel; supervisão de Álvaro Valãs. Petrópolis, RJ: Vozes, 1995. p. 104-123.

BENEVIDES, M.V. Palestra de abertura do Seminário de Educação em Direitos Humanos, São Paulo, 18 Fev.2000.

CONTEÚDO aberto. In: Wikipédia: a enciclopédia livre. Disponível em: <https://pt.wikipedia.org/wiki/DeclaraçãoUniversal dos Direitos Humanos>. Acesso em: 16 ago. 2019.

CONTEÚDO aberto. In: Wikipédia: a enciclopédia livre. Disponível em: <https://pt.wikipedia.org/wiki/Organização das Nações Unidas >. Acesso em: 16 ago. 2019.

DIAS, A. A. Da educação como direito humano aos direitos humanos como princípio educativo; Educação em Direitos Humanos: fundamentos teórico-metodológicos, 2007.

DOLABELA, F. Pedagogia Empreendedora. São Paulo: Cultura, 2003

FERNANDES. A.V. M. \& PALUDETO. M.; C.Cad. Cedes, Campinas, vol. 30, n. 81, p. 233-249, mai.-ago. 2010.

GRACIANO, M. Educação também é direito humano - São Paulo: Ação Educativa, Plataforma Interamericana de Direitos Humanos, Democracia e Desenvolvimento - PIDHDD, 2005.

KONDER, L. O futuro da filosofia da práxis: o pensamento de Marx no século XXI. Rio de Janeiro: Paz e Terra, 1992. 
MANACORDA, M. A. A Educação no Setecentos. In História da Educação - Da antiguidade aos nossos dias. $7^{\mathrm{a}}$ ed. São Paulo: Cortez, 1999.

MARTÍ, J. 1975. Obras completas. Ciudad Habana: Editorial Ciências Sociales.

PACHECO, A. S. V. A Pedagogia de Paulo Freire e a Pedagogia Empreendedora. Blumenau, SC: VI Colóquio Internacional Sobre Gestão Universitária na América do Sul, 2006.

SAVIANI, D. A Nova Lei da Educação: Trajetórias, limites e perspectivas. Campinas, SP: Autores Associados, 1997.

SÃO PAULO (ESTADO). Fundação Casa - Centro de Atendimento Socioeducativo ao Adolescente. Bases de Apoio Técnico para a Psicologia na Fundação CASA, agosto de 2019. Disponível em: 〈http://transparencia.fundacaocasa.sp.gov.br/portalInicio.aspx >, Acesso em 17 ago. 2019.

TEIXEIRA, A. Educação não é privilégio. Rio de Janeiro: José Olympio Editor, 1957. 